\title{
Produção de bairros segregados socioespacialmente: uma análise a partir do bairro Sapiranga, Fortaleza, Ceará
}

\author{
Production of socio-spatially segregated neighborhoods: \\ an analysis of the Sapiranga Neighborhood, Fortaleza, Ceará
}

Cindy Rebouças Palmeira [I]

\begin{abstract}
Resumo
A segregação socioespacial é o principal problema brasileiro. Em Fortaleza, no bairro Sapiranga, essa conformação evidencia-se através do contraste entre as residências de alto luxo e as invasões, que avançaram em sua área. Com o objetivo de investigar e compreender a ação dos agentes produtores desse espaço, para prever as possíveis consequências à cidade ao longo do tempo, foram utilizados o método de revisão bibliográfica e histórico documental, a coleta e interpretação de dados. Logo, conclui-se que os principais agentes produtores desse espaço segregado são o Estado, com os meIhores investimentos nas áreas direcionadas para a população da classe alta; o mercado imobiliário, que investiu em construções residenciais que valorizavam o "enclausuramento"; e as organizações criminosas instaladas no bairro, que restringem a circulação de pessoas em determinados locais, aprofundando a sensação de insegurança.
\end{abstract}

Palavras-chave: segregação sociespacial; desigualdade social; cidade; violência; planejamento urbano.

\begin{abstract}
Socio-spatial segregation is the main Brazilian problem. In the city of Fortaleza, in the Sapiranga neighborhood, this conformation is revealed by the contrast between luxury residences and the invasions that have advanced in their area. The objective of this study was to investigate and understand the action of the agents that produce this space in order to predict possible consequences to the city over time, using the method of bibliographic review and documentary history, as well as data collection and interpretation. It is concluded that the main producers of this segregated space are the State, as the best investments are made in areas targeted at the upper class, the real estate market, which has invested in residential constructions that value "cloistering", and the criminal organizations installed in the neighborhood, which restrict people's circulation in certain places and have deepened the feeling of insecurity.
\end{abstract}

Keywords: socio-spatial segregation; social inequality; city; violence; urban planning. 


\section{Introdução}

As relações entre a sociedade, a economia e o espaço urbano sempre estiveram presentes no meio acadêmico, sendo palco de debates e discussões devido a sua importância na vida citadina de todos. A forma econômica e política de como a cidade se desenvolve gera impacto direto na vida da população e na morfologia da malha urbana.

Essas relações, algumas vezes, passam despercebidas cotidianamente, porém os processos espaciais têm articulações bastante complexas, porque todas as tomadas de decisões dos agentes da produção do espaço envolvem, direta ou indiretamente, um fator-chave, o capital. A partir dessas ações, o espaço produz-se e mantém-se em constante transformação.

Segundo Correa (2018), o espaço urbano é a maneira como a sociedade se organiza, incluindo os mais variados usos, em forma de um local articulado e fragmentado, um complexo de símbolos e campos de lutas, refletindo a configuração social. Com isso, a abordagem do espaço urbano pode ser analisada a partir de vários segmentos que o englobam e em diferentes escalas.

Nos processos de urbanização das cidades, a diferenciação social sempre esteve presente com a divisão territorial e social do trabalho (Sposito, 2018). Diante disso, é evidente que na sociedade capitalista, na qual existe a livre troca de bens, serviços e propriedade privada, a divisão social seja prevista. Porém, esta se estabelece divergentemente no processo urbano, e a desigualdade social insere-se nesse contexto, devido às articulações, manobras e lógicas que permeiam o sistema econômico, moldando, assim, uma sociedade desigual. 0 processo de segregação socioespacial é visto, nas grandes cidades brasileiras, como efeito adverso de um desenvolvimento pautado pela segregação de classes, fenômeno também observado na capital cearense.

A cidade de Fortaleza é capital do estado do Ceará e tem população estimada em 2019 de 2.669.342 habitantes (IBGE, 2019). Quanto à sua situação geográfica, é considerada a 5a maior capital do Brasil, estando em localização estratégica em relação às demais capitais brasileiras, pois tem em sua posição territorial o principal ponto de entrada e saída de elevado tráfego de informações, sendo ela a capital mais próxima da Europa. A área total da cidade é de $314.930 \mathrm{~km}^{2}$, com divisão interna distribuída com 119 bairros (Prefeitura de Fortaleza, 2020). O bairro de estudo, Sapiranga, que está situado dentro de Fortaleza, tem a segregação socioespacial visível e intensa. Apesar do mesmo ser um bairro com a predominância de classes sociais bastantes distintas, não existe o convívio e a relação entre ambas. A desigualdade social deixa um abismo na relação cotidiana entre os diferentes, estabelecendo assim espaços divergentes e exclusivos em um mesmo perímetro.

O fluxo diário dos moradores da classe média e alta é feito, predominantemente, através da utilização de automóveis, isso possibilita transitar em maiores distâncias com maior facilidade. Deixar os filhos na escola, ir ao trabalho, fazer compras em supermercados, são ocupações simples e comuns na vida da população em geral. Entretanto esses simples fluxos revelam formas distintas de apropriação do espaço. Os moradores das favelas e das classes mais populares que habitam no bairro priorizam a utilização dos equipamentos públicos e comércios locais, situação que pode ser 
explicada pelo tempo gasto de deslocamento, tendo em vista utilizarem transportes públicos para locomoção.

Dessa maneira, as calçadas e os espaços públicos do bairro, em geral, estão prioritariamente ocupadas com grande número de pessoas transitando a pé e de bicicleta, apropriando-se do uso desses espaços. Porém, muitos desses espaços não estão adequados para a população, como, por exemplo, calçadas que não têm o desnível adequado ou têm a pavimentação comprometida. Além disso, reformas nas vias e ajustes em infraestruturas que atendem mais a um "público" que o outro foram realizadas, citando, aqui, a recente reforma no cruzamento da avenida Edilson Brasil Soares com avenida Leal Lima Verde.

A grande quantidade de condomínios horizontais que existem nesse bairro aprofunda a segregação socioespacial, tornando-se mais prejudicial para aqueles que se situam ao seu redor. Segundo Koch (2008), o elevado número de construções como essas gera, para o espaço urbano, uma série de impactos, como a segregação e exclusão socioespacial, através da homogeneidade social e das barreiras físicas impostas em suas fachadas e perímetro; a fragmentação do tecido urbano, com a implantação de unidades autônomas descontínuas na malha urbana; a desvalorização e privatização do espaço público, entre outros.

0 presente trabalho analisou e interpretou o fenômeno de segregação socioespacial à luz dos processos de produção espacial que aconteceram no bairro Sapiranga, compreendendo a ação dos agentes produtores do espaço. Tendo em vista a grande desigualdade social estabelecida nesse bairro e o fato de ele ganhar destaque por seu aumento populacional e pelos índices altos de violência, justifica-se a investigação, por tratar-se se um problema de cunho social, econômico e político.

Indagações sobre o fenômeno consolidado no bairro Sapiranga produzem o ponto de partida para esta pesquisa: "Como aconteceram as ações dos agentes produtores do espaço para desencadear o atual processo de segregação socioespacial?"; "Por que ocorreu uma grande valorização no valor da terra se mais da metade da população é considerada de baixa renda?"; "Como o bairro Sapiranga se tornou um perfil de bairro controlado pela violência se há poucos anos era considerado um bairro para moradores da classe média e alta?"; e "Por que a Sapiranga é um bairro misto de classes sociais e a segregação espacial prevalece?".

Portanto, parte-se da necessidade de interpretar as ações que estão por trás desse fenômeno, utilizando pesquisa bibliográfica, levantamento, análise, síntese e interpretação de dados, obtendo, assim, ferramentas para discutir esse fenômeno e seus possíveis resultados futuros ao longo do tempo.

\section{Produção de espaços socialmente segregados}

Dentro das cidades, há articulações entre pessoas, matérias, informações, serviços e uma extensão de elementos. Segundo Lojkine (1997 apud Santos, 2013), a cidade é classificada como um "valor de uso complexo", ou seja, ela caracteriza-se por ser um espaço com vasta variedade nesses valores que estão em 
constante movimento. Desse modo, entendendo o contexto da economia capitalista, no qual a terra é considerada uma mercadoria e há variados interesses partindo dos agentes produtores do espaço, estruturam-se fenômenos espaciais diversos que geram conflitos de apropriação territorial, desencadeando as segregações urbanas.

Os processos de segregação socioespacial envolvem a lógica de produção do espaço, sob a lógica da separação e da distinção de espaços de convívio de pessoas. Com isso, compreender o processo de urbanização do ambiente segregado auxilia na descoberta das circunstâncias e dos motivos da segregação.

No espaço urbano, pode-se encontrar locais segregados socialmente e espacialmente. Como o próprio nome já indica, segregação define-se como "afastamento ou separação" (Ribeiro, 2018), desse modo, quando pensamos em segregação socioespacial logo vêm à mente os ambientes afastados, nas periferias urbanas, sem assistência governamental e marcados pela pobreza. Essa é uma realidade que existe em muitas cidades brasileiras, porém, não existe apenas com esse perfil: é possível e bastante comum existir segregação socioespacial próximo a centros urbanos onde há oferta de infraestrutura, produtos e serviços.

No presente estudo, foi considerada a análise espacial e das estruturas sociais, com o propósito de construir um texto acadêmico sobre a produção de um espaço urbano que se caracteriza por ser social e espacialmente segregado em seu interior. Local este que passou por transformações urbanas, ambientais e sociais, ao longo das décadas, e que ganhou visibilidade nos últimos anos por estar associado a um bairro controlado por facções criminosas e, ao mesmo tempo, por posicionar-se em uma região nobre na cidade de Fortaleza.

\section{A produção do espaço urbano}

De acordo com Souza (2013), em uma conceituação mais simplificada, o espaço geográfico é aquele conhecido como a superfície terrestre que se diferencia do espaço social, que é aquele moldado e transformado pela sociedade. Avançando a teoria, o autor afirma que o espaço geográfico é um local profundamente social, e as articulações salientes são as relações sociais. Então, o espaço geográfico é entendido como um conceito mais amplo e o espaço social, como um conceito mais específico; os dois estão associados e se fazem categóricos em sua compreensão.

Corrêa (1989, p. 7) afirma que o espaço urbano configura o conjunto de usos na terra, com múltiplas funções, como comercial, residencial, institucional, educativo entre outras. As áreas do urbano interligam-se e fragmentam-se, mantendo relações fracas ou fortes entre elas (apud Damião, 2014, p. 58). A forma organizacional desses espaços está sempre mudando e está intrinsecamente relacionada com a divisão espacial do trabalho, com a disposição espacial da infraestrutura e com o padrão de segregação e autossegregação (Souza, 2013). Essa organização resulta da relação espaço e sociedade, com o foco na territorialidade, ou seja, na projeção de espaço geográfico desejado.

A produção do espaço não é necessariamente uma criação inicial, pode ser entendida também como reprodução ou até repetição 
de ações e consequências geradas por seus agentes de produção (ibid.). Esses agentes são: o Estado, os proprietários fundiários, os promotores imobiliários, os proprietários dos meios de produção e os grupos sociais excluídos (Corrêa, 1995).

Na produção do espaço, o Estado capitalista é o agente regulador dos demais agentes, que contém múltiplas funções importantes, que permeiam entre diferentes interesses e conflitos da política, da economia e da sociedade. Porém, a ação tendenciosa do Estado reflete em benefícios de interesses dominantes, ou seja, não há imparcialidade no marco jurídico regulador da produção desses agentes e no uso do espaço. Desse modo, as relações que esse agente estabelece com outros, como, por exemplo, empreiteiras, proprietários de terras, bancos, empresas industriais e de consultoria, infiltram "mecanismos de negociação, cooptação e clientelismo, aos quais a corrupção não é estranha" (Corrêa, 2018).

Porém, de modo geral, essa produção se estabelece com a ação do homem ou de quaisquer agentes sociais que estejam dispostos a estabelecer ocupação de um território ou tenham interesses e estratégias espaciais concretas, podendo gerar conflitos entre eles mesmos, evidenciados no resultado da produção de localizações, que se diferenciam por valor, legislação, infraestrutura e investimentos (Villaça, 2001; Corrêa, 2018). Portanto, a diferenciação entre essas localizações é alvo da produção de disputas de território e de interesses capitalistas. Nesse contexto, as transformações e reproduções do espaço urbano do Brasil apresentam dilemas territoriais frequentes, como a segregação socioespacial, oriundos de uma grande desigualdade social e produção espacial segregacionista.

\section{Segregação socioespacial}

A segregação socioespacial caracteriza-se pela concentração de um grupo social em um espaço ou localização geográfica específica. A área que concentra a camada mais alta da classe social é privilegiada com melhor acesso de infraestrutura, investimentos públicos e privados, havendo, desse modo, uma dominação desigual das vantagens oferecidas no espaço urbano (Villaça, 2001).

Essa segregação pode ser voluntária, quando o indivíduo decide habitar próximo às outras pessoas de sua classe social por iniciativa própria; e involuntária, quando, por forças externas, o indivíduo passa a habitar em uma localização da cidade (ibid., 2001). Sposito (2018) ressalta que, a conformação mais comum da segregação socioespacial se dá pela autossegregação dos mais favorecidos economicamente, deixando evidente a problematização das desigualdades e impossibilitando o diálogo e a socialização entre os diferentes.

Villaça (2001) revela que a tendência do crescente aumento de segregação de classes sociais em determinados setores das metrópoles no Brasil ocorreu desde o século XIX. Com isso, as classes acima da média de renda escoIheram se segregar espacialmente, e o centro de serviços e comércio, através do mercado imobiliário, passou a desenvolver-se em sua direção, formando os "novos centros". 
Nessas metrópoles, as disputas de camadas sociais pelo espaço é a força mais poderosa de estruturação, uma vez que as vantagens de localização são decisivas para o melhor desenvolvimento dos indivíduos, que, por sua vez, disputam a partir de suas necessidades, enquanto distintas classes sociais. Essa disputa se revela primordial por sua vantagem de acessibilidade no deslocamento do ser humano. Sendo assim, a vantagem mais importante é a da localização "pura" entre trabalho, moradia, consumo e mercadoria, pois a proximidade é vital para otimizar o tempo de deslocamento e energia (ibid.).

Para o ser humano, é proveitoso "seguir o capital", ou seja, aproximar-se das oportunidades de emprego e das condições de consumo, porém, para isso, é fundamental a possibilidade do deslocamento individual dentro das cidades. Portanto os transportes são essenciais para a estruturação do território, pois, através deles, torna-se viável percorrer grandes percursos. Assim, compreende-se que os investimentos públicos ligados ao sistema viário são características importantes que definem segregação socioespacial, pois a localização passa a ser o produto de disputa entre classes sociais, na medida em que ela é definida e qualificada por sua acessibilidade e por serviços públicos disponíveis na região (ibid., 2001).

Sposito (2018) faz referência à cidade atual como um ambiente com inexistência de unidade espacial, pois há uma descontinuidade nos tecidos urbanos com ações e apropriações parcelares dos espaços. Essa afirmação é justificada pela autora em razão da presença das distintas movimentações e posses espaciais, ou seja, das diferentes preferências das localizações de habitação, trabalho, estudo e lazer e seus devidos percursos diários. Essas estruturações são determinadas por escolhas particulares, condições individuais e variadas formas de segmentação históricas, segundo o perfil socioeconômico e cultural, a faixa etária, as preferências de acesso a bens e serviços entre outras variantes.

É preciso deixar claro que, quando os desiguais economicamente ocupam territórios de proximidade geográfica, o que é comum, a segregação socioespacial não se torna inexistente, pelo contrário, os sistemas de segurança urbana ou privada propiciam o aprofundamento dessa segregação. Sposito (ibid., p. 141) frisa que essa adjacência entre eles só é possível:

[...] por causa dos muros e dos sistemas de controle de acesso a espaços privados residências (loteamentos fechados e condomínios horizontais e verticais), espaços industriais (condomínios de empresas como o Techno Park e outros), comerciais e de serviços (como os shopping centers, centros empresariais e de negócios, espaços de lazer e entretenimento), bem como a livre circulação nos espaços públicos. Estou me referindo, ao mesmo tempo, às guaritas, aos sistemas de câmeras que nos cerceiam e nos vigiam [...].

Os interesses de consumo das camadas de alta renda dominam as vantagens de estruturação do espaço urbano interno, isto é, apropriam-se de mais possibilidades, recursos e frutos do espaço urbano desigualmente. Nesse cenário, encontra-se uma tensão permanente entre agentes sociais possuidores ou não de capital em prol da habitação e da terra 
urbana nas melhores localizações (Corrêa, 2018). Portanto, as disputas e os conflitos pela apropriação dos espaços e tempos de deslocamento da força de trabalho e consumo processam-se em estruturas espaciais, como a segregação espacial.

\section{Metodologia}

Esse estudo se baseia na análise e interpretação dos processos espaciais precedentes da segregação socioespacial do bairro da Sapiranga/Coité, na cidade de Fortaleza, Ceará, Brasil, com o objetivo de compreender a ação dos agentes e as consequências para a vida da população local. Para conferir criticidade científica a este estudo, foram realizadas as seguintes etapas: estabelecimento do objetivo da análise; revisão bibliográfica e histórico-documental; coleta de dados e informações estatísticas e gráficas; análise e síntese dos resultados; e sua apresentação e discussão.

\section{Revisão bibliográfica e histórico-documental}

Foi realizada uma investigação em livros, documentos, artigos, reportagens, dissertações e teses sobre o tema do estudo, obtenção de referências históricas e fundamentação teórica, apresentando conceitos e teorias, com a finalidade de fundamentar e compreender as temáticas relacionadas com o problema de pesquisa, utilizando autores reconhecidos para o tema proposto.

\section{A coleta de dados e informações estatísticas e gráficas}

A coleta foi elaborada para compor um banco de informações geográficas socioeconômicas, ambientais, históricas e políticas, necessárias para comparar as estruturas e as características do local de estudo. Como o principal fator de segregação no Brasil é o socioeconômico (Villaça, 2001), a utilização do Censo Demográfico do IBGE de 2000 e 2010, foi fundamental nesta pesquisa, servindo de instrumento para análise das modificações ocorridas durante esses anos. Foram utilizados os dados das tabelas e gráficos produzidos pelo Instituto de Pesquisa e Estratégia Econômica do Ceará (Ipece).

\section{Análise e síntese dos resultados}

Para guiar essas análises, formularam-se as seguintes questões: "Como aconteceram as ações dos agentes produtores do espaço para desencadear o atual processo de segregação socioespacial?"; "Por que ocorre uma grande valorização no valor da terra se mais da metade da população é considerada de baixa renda?"; "Como a Sapiranga se tornou um perfil de bairro controlado pela violência se há poucos anos era considerado um bairro para moradores da classe média e alta?"; e "Por que a Sapiranga é um bairro misto de classes sociais, e a segregação socioespacial prevalece?".

Com isso, pôde-se concentrar nas informações mais relevantes para atender ao objetivo do trabalho e organizar e editar os mapas com os dados mais necessários para compreensão e interpretação da análise descritiva. 
Figura 1 - Localização do bairro Sapiranga

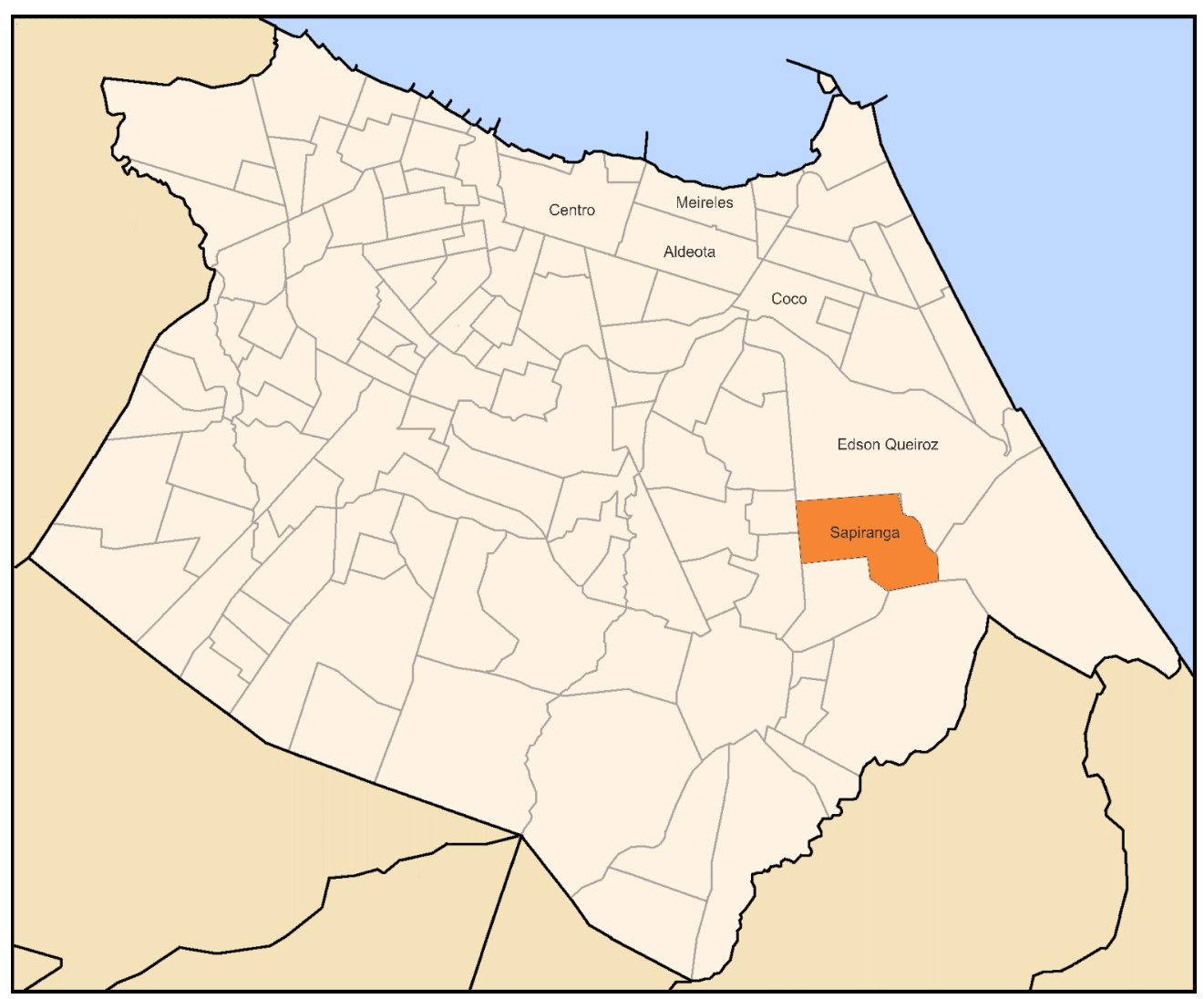

Fonte: elaborado pela autora. 


\section{Apresentação e discussão}

Os dados, depois de tratados, foram correlacionados com a pesquisa bibliográfica, evidenciando a configuração dos processos espaciais do bairro Sapiranga/Coité, dando, assim, um embasamento científico para a discussão acerca do assunto em questão.

\section{Análise dos processos de produção do bairro}

O bairro Sapiranga/Coité localiza-se na cidade de Fortaleza, Ceará, possui 482,74 hectares e 32.154 habitantes e está situado no perímetro da Secretaria Executiva Regional (SER) VI (Prefeitura de Fortaleza, 2018b). Ele tem um índice de desenvolvimento humano (IDH) considerado muito baixo, com apenas 0,33 (ibid., 2018).

Inicialmente, esse bairro foi predominantemente voltado para uma camada da sociedade economicamente acima da média, estando hoje entre os bairros que experimentam valorização imobiliária. Está situado no lado sudeste da cidade (Figura 1) e sofreu grandes transformações nas últimas décadas, passando por mudanças de usos e apropriações do espaço. A população é economicamente desigual, retratando as segregações sociais no interior do espaço urbano de Fortaleza.

Fazendo um comparativo nos dados habitacionais dos Censos Demográficos do IBGE, observa-se o expressivo aumento de moradores desse bairro, passando de 9.130, no ano de 1991 para 32.158, no ano 2010, chegando próximo a quadruplicar o total de habitantes (IBGE, 1991, 2000 e 2010).
Esse permanente aumento populacional que se estendeu até os dias atuais traduz-se nas circunstâncias histórico-espaciais ocorridas desde a última década do século $X X$, quando a valorização imobiliária do bairro alavancou, com a presença da construção de casas e condomínios fechados voltados para a classe média e alta, com os investimentos na infraestrutura e com a implantação de equipamentos públicos e privados, que, por sua vez, estão interligados com a expansão da avenida Washington Soares e com crescimento urbano direcionado para o lado leste de Fortaleza (Oliveira, Meneleu Neto e Oliveira Neto, 2018).

Portanto, os privilégios que a localização pode oferecer para quem nela reside atraíram populações de diversas classes sociais, o que resultou em processo de ocupação acelerado, conjuntura que refletiu um cenário de bairro desigual e misto socialmente. Hoje se estabelece grande quantidade de favelas que compartilham a mesma localização com os condomínios de luxo e as casas de classe média e alta, evidenciando as diferentes maneiras de se apropriar do espaço público e de estipular limites não físicos.

\section{Expansão urbana em direção ao eixo leste}

Desde o final do século XX, houve um aumento acelerado na população de Fortaleza, com a criação da Região Metropolitana de Fortaleza (RMF). Esse crescimento primordial foi vinculado ao destaque da capital como um ambiente economicamente propício ao desenvolvimento, pois, naquele momento, acontecia uma nova reestruturação no sistema produtivo e 
Figura 2 - Mapa da RMF com os vetores de expansão urbana - 2016

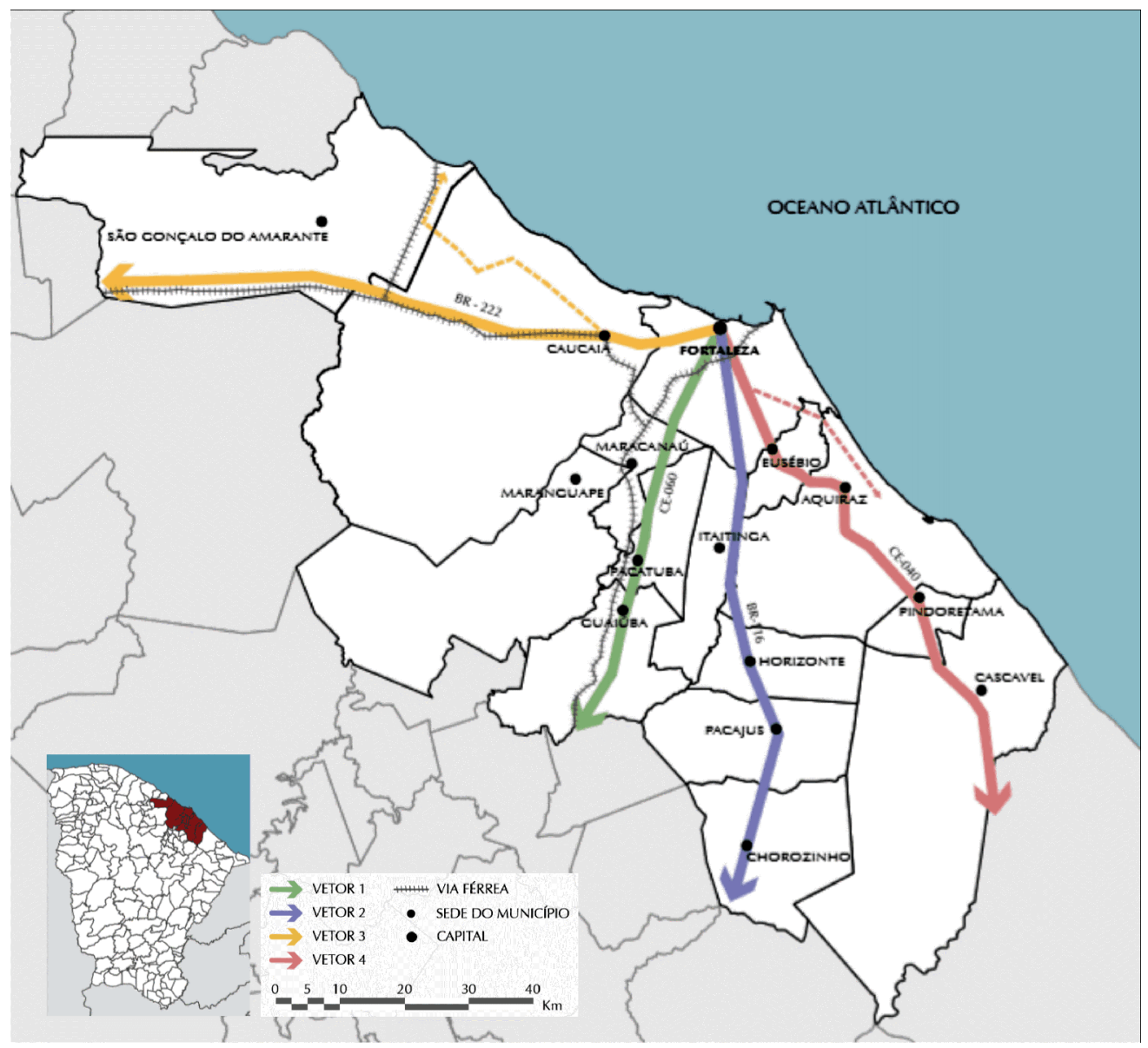

Fonte: Diógenes (2016).

na industrialização da capital cearense. Essas transformações progrediram em mudanças no âmbito social e no aumento de infraestrutura na cidade (Costa e Amora, 2015). Logo, pode-se afirmar que as alterações socioespaciais que ocorreram na RMF impactaram na configuração interna da cidade de Fortaleza, ou seja, o crescimento da metrópole e suas relações espaciais motivam novas formas urbanas e organizações espaciais da cidade.
Nesse sentindo, Santos (2013) afirma que as dinâmicas decorrentes do crescimento das cidades, mais precisamente das produções espaciais relacionadas à habitação, estão associadas aos vetores de expansão metropolitana que são conceituados durante esses processos de desenvolvimento metropolitano. Esses vetores podem ser definidos como importantes vias de transportes que direcionam os fluxos no percurso da expansão, o que, além de 
propiciar a viabilização do crescimento metropolitano, ainda influencia no processo de segregação socioespacial, por meio do conflito da produção social versus apropriação privada, uma vez que os perímetros de tais vetores passam a ser mais disputados e ocupados por comércios e residências.

O crescimento da RMF permanece em curso e é estruturado nos eixos de metropolização a partir de quatro vetores viários (Figura 2), estando o vetor quatro situado no quadrante sudeste da metrópole que fica direcionado para os municípios de Aquiraz e Eusébio (Diógenes, 2016).

Nesse vetor 4, estende-se a avenida Washington Soares, que passa pela área de estudo, indo desde o bairro Edson Queiroz até o bairro Messejana. Por volta do final da década de 1970, ocorreram melhorias de infraestrutura nessa região, por conta da construção da avenida, que daria acesso aos novos equipamentos ali implantados. 0 direcionamento da expansão urbana é evidente com a instalação de grandes equipamentos urbanos e alargamentos de vias, através de investimentos do Poder Público junto com o setor privado. Esse fato valorizou os bairros ao redor, favorecendo o processo de crescimento nas habitações da classe média e alta para as adjacências da avenida, reforçando uma nova centralidade (ibid.). Em vista disso, o bairro Sapiranga, local ainda pouco habitado e dotado de muitos vazios e pouca infraestrutura, ganhou desenvolvimento e o estabelecimento de condomínios fechados. Essas transformações foram de encontro com a paisagem das favelas e de conjuntos habitacionais que havia nas proximidades daquela região, ambiente que, segundo Lopes (2016), convertia-se em um subúrbio privado de classes médias.
Os "novos centros" ou novas centralidades das metrópoles são orientados para a classe de alta renda, mas são neles que se concentram as localizações dos empregos das camadas de baixa renda (Villaça, 2001). Assim, é possível associar que a grande quantidade de equipamentos comerciais gera uma grande quantidade de empregos, logo, a proximidade e o fácil acesso a eles são convenientes e alvos de competição.

Ao longo da nova centralidade, constata-se a instalação de vários equipamentos de grande porte, como shoppings centers, universidades, centro de eventos, centros comerciais, grandes empreendimentos entre outros. Fator atrativo que torna as proximidades dessa localização valorizadas por motivos de mobilidade e tempo de deslocamento.

\section{Mercado imobiliário}

A expansão da RMF para o lado leste da cidade possibilitou, para o mercado imobiliário, grandes vantagens econômicas, com a valorização do metro quadrado das regiões que receberam investimentos de infraestrutura. Segundo Lopes (2016), nesse momento, a região na qual se situava o bairro de estudo, estava incluída no marketing estratégico denominado "Região da Água Fria", no qual não tinha demarcação territorial, mas englobava proximidades do bairro Edson Queiroz no sentido do crescimento da cidade ao longo da avenida Washington Soares.

O bairro Água Fria, hoje nomeado de Edson Queiroz, faz limite com o bairro Sapiranga e foi por ele que iniciou o processo de crescimento populacional, depois se estendendo para os demais bairros no sentido leste. Após o 
Quadro 1 - Valor do metro quadrado por bairro nos anos de 2005/2006 e 2010/2011

\begin{tabular}{|l|c|c|c|c|c|c|}
\hline \multirow{2}{*}{ Bairro } & \multicolumn{2}{|c|}{ 2005/2006 } & \multicolumn{2}{c|}{ 2010/2011 } & \multicolumn{2}{c|}{ \% Crescimento-5 anos } \\
\cline { 2 - 7 } & Mínimo-R\$ & Máximo-R\$ & Mínimo-R\$ & Máximo-R\$ & Mínimo & Máximo \\
\hline Meireles & 600 & 4.000 & 3.000 & 12.000 & 400 & 200 \\
Aldeota & 400 & 700 & 1.200 & 2.000 & 200 & 186 \\
Edson Queiroz & 180 & 240 & 1.000 & 3.500 & 456 & 1.358 \\
Sapiranga & 150 & 300 & 1.000 & 3.500 & 567 & 1.067 \\
\hline
\end{tabular}

Fonte: Câmara de Valores Imobiliários do Ceará, 2011, apud Lopes (2016).

ano de 1999, quando houve o alargamento da avenida Washington Soares, o aumento populacional do bairro quase triplicou, passando de 9.164 habitantes contabilizados no Censo de 1991 para 23.399 habitantes na contabilização do Censo de 2000 (Salvador e Carleial, 2010). Aliado a isso, as construções de condomínios fechados na "Região Água Fria" eram sinônimos de status social, por serem locadas na nova área valorizada da cidade (Lopes, 2016).

A valorização do capital financeiro nessa região foi marcada pela incorporação dos condomínios fechados que se atrelavam ao valor de uso da casa de condomínio, como elucidações de local agradável e longe do "caos urbano", influenciando, assim, no valor do metro quadrado a ser pago naquele local. Segundo Corrêa (1995), propriedades com valor de status social elevado têm um uso remunerador com grande renda fundiária, por conta do valor de troca que está agregado, ou seja, o valor de troca da terra é mais valioso para proprietários fundiários e promotores imobiliários do que o valor de uso.

Entretanto, a construção desses condomínios fechados pode ser explicada por ser uma estratégia de minimizar os gastos das incorporadoras com a padronização da construção de casas, em um modo de produção em "série" que dilui os gastos fundiários (Lopes, 2016) e aumenta o acúmulo de lucro. Corrêa (1997) afirma que os promotores imobiliários são todos aqueles agentes que fazem operações de construção, financiamento, incorporação de imóvel, comercialização da mercadoria em dinheiro com o aumento do lucro, sendo estes, agentes importantes para o processo de produção espacial.

Sendo assim, o investimento do mercado imobiliário nesse setor da cidade beneficiou-se do investimento do Estado na instalação de infraestrutura local e direcionou o aumento do preço da terra, valendo-se da valorização das amenidades físicas do bairro, como as lagoas, o mangue e a ampla arborização. Esses recursos naturais foram usados como propagada de desejo de consumo, por parte dos empreendedores do mercado imobiliário, com o intuito de valorizar o seu empreendimento e atrair investidores e compradores.

Tendo isso em vista, Salvador e Grangeiro (2014) apontam que a indústria da construção civil e as diretrizes emanadas pelo Estado têm um papel importante para a produção 
dos espaços urbanos criados, nos quais a valoração da natureza se torna mercadoria, ao mesmo tempo que sufocam as áreas verdes e popularizam territórios ainda livres. Essa estratégia de venda do mercado imobiliário no bairro Sapiranga foi bastante disseminada nesse meio, desde a ocupação do bairro até os dias atuais. Os novos condomínios e casas de residências têm as publicidades e propagandas focadas no potencial ambiental da região, apesar de seus compradores desfrutarem mais dos espaços livres dos condomínios do que dos espaços públicos com reservas ambientais.

De acordo com Souza (2009 apud Oliveira, Meneleu Neto e Oliveira Neto, 2018), as propriedades ambientais que esse bairro possui têm características hídricas importantes para a cidade de Fortaleza, com a existência da lagoa do Coité e da lagoa da Sapiranga, que deságuam no rio Cocó. No seu diagnóstico geoambiental, ressaltou, ainda, que ele é predominantemente classificado de tabuleiro pré-litorâneo.

Outro fator estratégico do mercado imobiliário para atrair clientes para esses condomínios fechados foi a ideia de um ambiente confortável e seguro, que explorou uma parcela da sociedade que anseia desfrutar de espaços privatizados no dia a dia, que se estendem além da habitação. Em resposta a esses novos desejos e necessidades, atualmente os condomínios fechados são a forma urbana que mais movimenta esse setor (Melgaço, 2012).

Raposo (2008) considera os condomínios fechados uma tipologia de segregação singular, pois há, em sua estrutura, uma barreira física que segrega os demais e autossegrega aqueles que ali habitam de maneira voluntária, em busca de segurança. Na maioria dos condomínios fechados, o perfil social dos residentes é um fator influenciador na determinação de sua escolha, ou seja, a convivência entre vizinhos de igual classe social é a mais preferível.

Os impactos segregacionistas causados por esse tipo de construção no bairro Sapiranga são físicos, através das barreiras impostas na cidade, e sociais, com a minimização de integração social pelos residentes desses "enclaves", que usufruem dos benefícios privados ofertados dentro dos condomínios, autossegregando-se do meio exterior. Esses benefícios são a segurança privatizada, que gera um espaço tranquilo e sem preocupações com a entrada de desconhecido em seu perímetro fortificado; recursos da área de lazer interna entre outros serviços e equipamentos ofertados.

\section{As favelas}

Os agentes produtores do espaço urbano podem ser os grupos sociais excluídos, que são aqueles que não possuem poder aquisitivo suficiente para comprar ou alugar legalmente e formalmente um imóvel ou, por outras razões, não conseguem alcançar as condições e as oportunidades básicas. Assim, as possibilidades de escolha de moradia tornam-se restritas, sendo elas, favelas, cortiços e conjuntos habitacionais viabilizados pelo Poder Público (Corrêa, 1995).

Segundo Corrêa (2018) favela caracteriza-se por uma invasão e ocupação de terras públicas ou privadas. Quando essas ocupações de terras invadidas são em bairros inicialmente produzidos pela classe de alta renda ou em suas proximidades, propiciam o acesso mais fácil das classes populares a uma parcela de vantagens que há nesses espaços (Villaça, 2011). 
Figura 3 - Situação dos assentamentos quanto à natureza da área ocupada em aberturas de vias e faixas de domínio, na Sapiranga, 2012

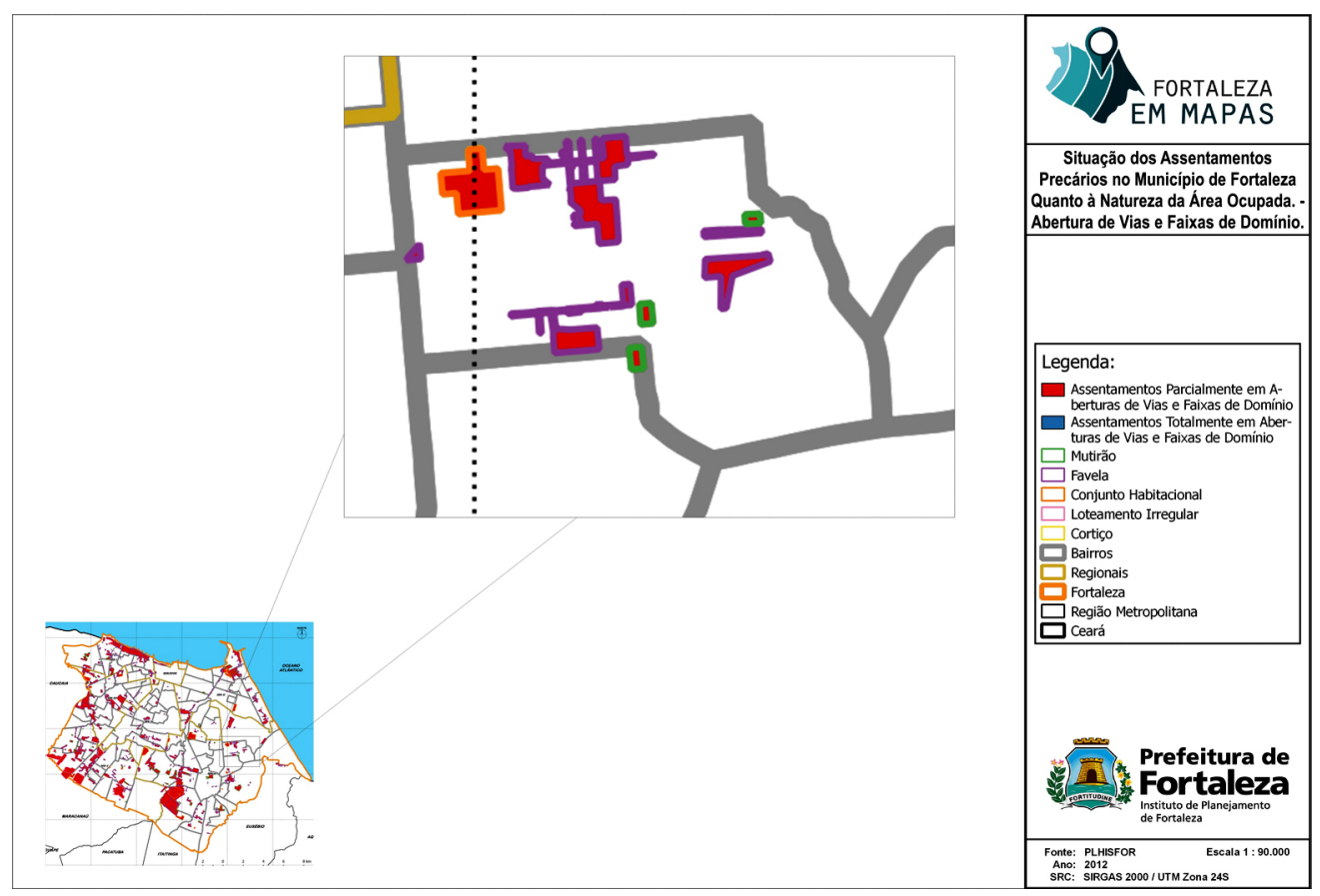

Fonte: Prefeitura de Fortaleza (2018a). Editado pela autora.

O bairro Sapiranga tem um crescente número de assentamentos precários, sendo a maior quantidade deles, comparado com o dos demais bairros incluídos no perímetro da Regional VI, totalizando 29. São eles: Cachorro Morto, Conjunto Alvorada, Lagoa Seca ou Alvorada, Dendê (Q. 38), rua Marcelino Lopes, Favela da Conquista ou Alecrim, rua Brigadeiro Haroldo Veloso, rua Afonso Pena, Vitória, Cidade Leste, vila Uruca, rua Conselheiro Gomes de Freitas, Pedro Miguel (Lagoa Seca), Nosso Sr. do Bonfim, Parque Novo Paraiso Trecho II, Dendê (Q. 168) Comunidade Lagoa do Coité,
Lagoa da Sapiranga, Afonso Pena, rua da Faice, rua Pedro Miguel, Comunidade Uruca, Parque Novo Paraiso ou Olindina Moreira, rua Guiomar, Riacho Doce, Barro Duro, Francisca Bezerra (Barro Duro), travessa José Pedro e travessa São Lucas (Prefeitura de Fortaleza, 2018b).

A área de Zonas Especiais de Interesse Social - Zeis foi estabelecida no bairro, no intuito de legitimar a diversidade dessas ocupações que não seguem os padrões de construção das Leis de Uso e Ocupação do Solo ou das Leis de Zoneamento. Há Zeis tipo 1, 2 e 3, sendo a Zeis 3 com maior extensão geográfica. Estas são 
Figura 4 - Classificação das Zonas Especiais de Interesse Social, no bairro Sapiranga, 2012

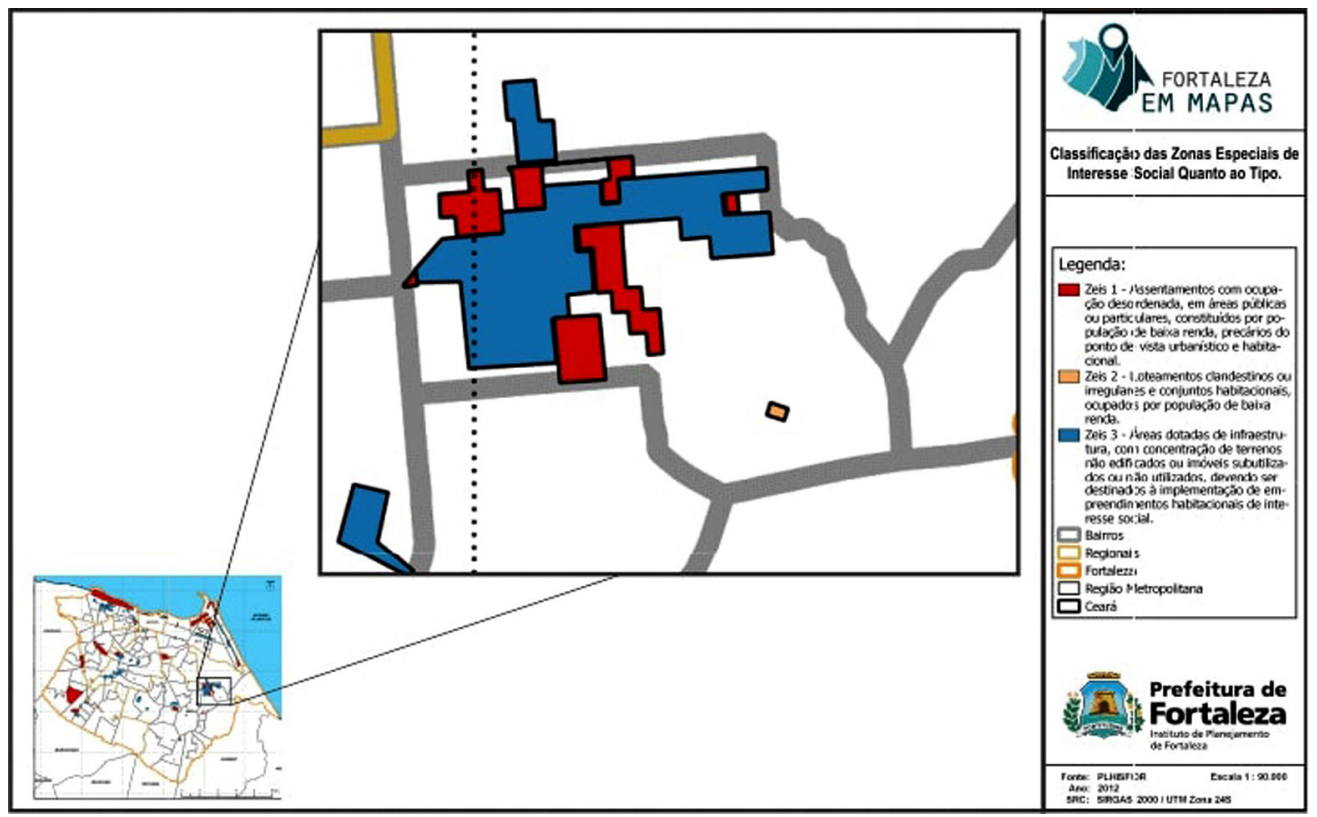

Fonte: Prefeitura de Fortaleza (2018a). Editado pela autora.

consideradas "áreas dotadas de infraestrutura com concentração de terrenos não edificados ou imóveis subutilizados ou não utilizados, devendo ser destinados à implementação de empreendimentos habitacionais de interesse social". Com relação à Zeis 2 consideram-se os "assentamentos com ocupação desordenada, em áreas públicas ou particulares, constituídos por população de baixa renda, precários do ponto de vista urbanístico e habitacional" (Prefeitura de Fortaleza, 2018a).
Nessa condição, a morfologia das habitações, vielas e ruas internas faz parte da paisagem urbana, agregando $60 \%$ da população dos residentes do bairro (Oliveira, Meneleu Neto e Oliveira Neto, 2018). Essa população está abrigada em ocupações irregulares, casas precárias ou moradias que não seguem os padrões arquitetônicos. Consegue, com isso, desviar-se dos altos valores estabelecidos pelo mercado imobiliário formal, mas estão do mesmo modo presentes e pertencentes à paisagem urbana. 
Figura 5 - Mapa com classificação do aumento de violência de 2016 a 2017

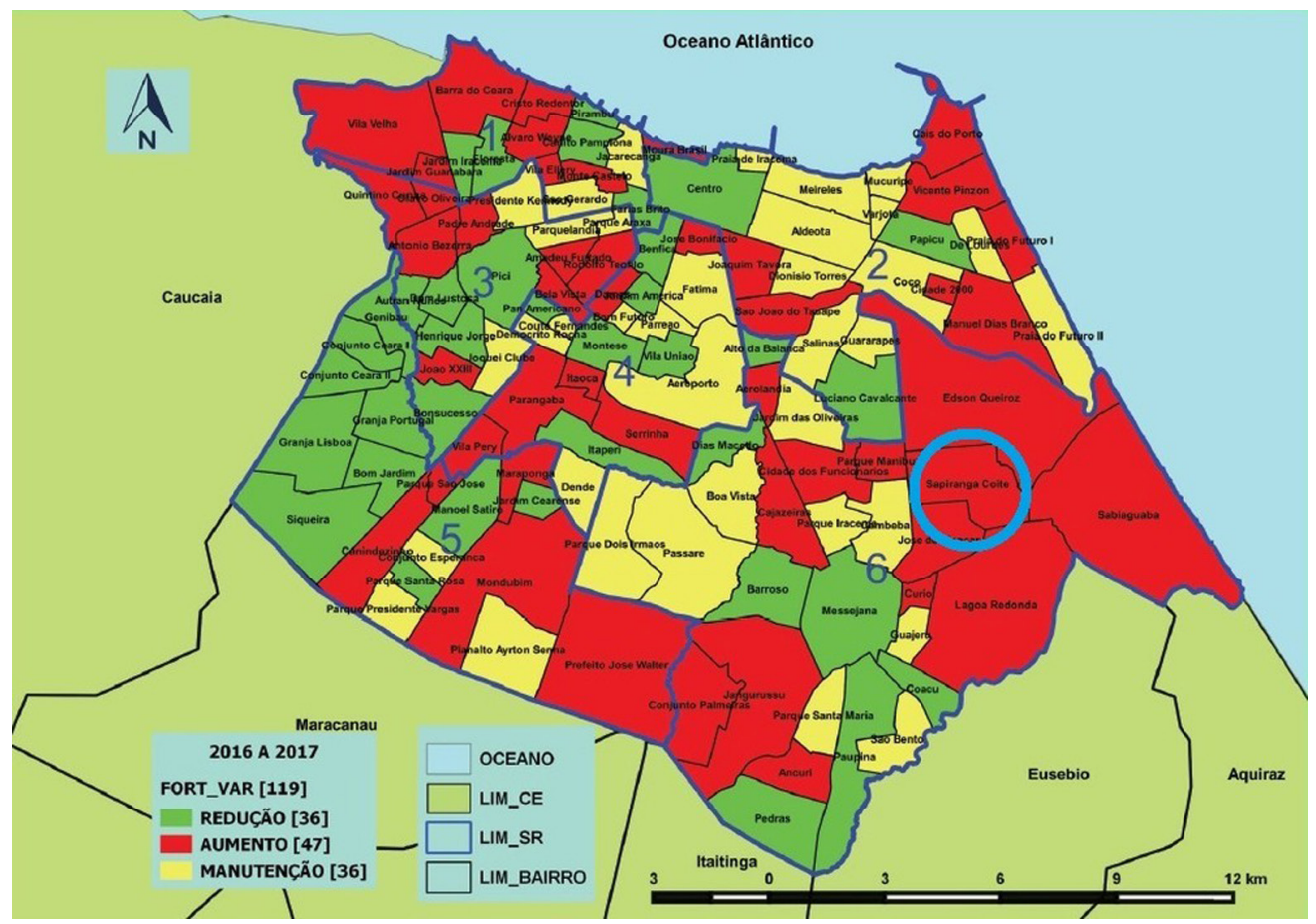

Fonte: Globo.com, Ceará, em 2017.

Loteamentos populares nas periferias urbanas e as produções de favelas podem ser considerados uma produção de "espaço vernacular". Estes possuem agentes particularmente ligados a essa estrutura de dinâmica socioespacial; a título de exemplo, os agentes sociais vinculados à informalidade imobiliária e à criminalidade (Corrêa, 2018).

Teixeira (2017), para uma matéria publicada no jornal G1 Ceará em novembro de 2017, divulgou o expressivo aumento na violência dentro do bairro Sapiranga, elencando- o como um dos mais violentos (Figura 5) da região. As disputas entre duas organizações criminosas repercutiram em insegurança para todos os moradores do bairro. Pichações nos muros, identificam essas organizações e comunicam as regras para poder entrar em alguns locais.

A infiltração dessas organizações criminosas em aglomerados da cidade de Fortaleza-CE e, sobretudo, no bairro Sapiranga, ganha uma proporção desastrosa, tornando-se um problema generalizado, tanto pela real insegurança quanto pelo aumento dessa sensação de insegurança que aprofunda a segregação, pois paradigmas e estereótipos historicamente enraizados sobre as favelas prevalecem no imaginário das demais populações. 


\section{Conclusão}

No bairro Sapiranga, a ação de agentes produtores do espaço, como o Estado, os promotores imobiliários, os grupos sociais excluídos e a ideologia, moldou a morfologia e as relações sociais que atualmente encontram-se lá.

O papel do Estado foi fundamental durante o período de intensa ocupação do bairro, pois o direcionamento de investimentos em infraestrutura de acessos e equipamentos públicos, durante o período de expansão urbana, atraiu os moradores para a região.

As classes economicamente acima da média partiram em direção à nova centralidade que se encontrava nas proximidades da avenida Washington Soares e às vantagens desse espaço, como a oferta de empregos, as proximidades de escolas, as universidades e o centro de serviços e comércio, que foram proporcionadas, pelo Estado e por empresas privadas. Essas vantagens serviram de circunstância para atração de uma camada mais baixa.

O Estado não para de agir e caminhar entre todos os agentes produtores do espaço. A facilidade de crédito para financiamento incentiva a compra e produz o espaço urbano. A ação do mercado imobiliário com a construção de condomínios fechados nessa região enraizou a autossegregação e valorizou essas habitações com alto valor de uso agregado.

A mediação de conflitos entre os agentes é papel do Estado, que também tem o poder de intensificar ou de proibir alguns tipos de segregação. Com a frente do comando de organizações criminosas no bairro e o considerável aumento da violência, as pessoas tendem a praticar a autossegregação em suas residências, como um refúgio de segurança. Desse modo, os que têm mais poder de compra privatizam seus espaços de convivência, trabalho e lazer, deixando de usufruir a cidade, que acaba ficando para aqueles quem não possuem muitas opções de escolha.

Quando o investimento do Estado é direcionado para áreas ou equipamentos do bairro que são apropriados por população mais alta, os problemas da segregação repercutem para a vida dos menos favorecidos, uma vez que as melhores oportunidades são direcionadas e desviadas intencionalmente.

Nos bairros mistos de classes, pode haver vantagens por desconcentrar a pobreza de um só local, mas essa realidade não tem intensificado a integração social, uma vez que o apego da população a sentimentos autossegregacionista prevalece.

\section{[I] https://orcid.org/0000-0002-6757-723X}




\section{Referências}

CORRÊA, R. L. (1995). O espaço urbano. Rio de Janeiro, Ática.

(2018). "Sobre agentes sociais, escala e produção do espaço: um texto para discussão". In: CARLOS, A. F. A.; SOUZA, M. L. de; SPOSITO, M. E. B. (orgs.). A produção do espaço urbano: agentes, processos, escalas e desafios. São Paulo, Contexto.

COSTA, M. C. L; AMORA, Z. B. (2015). “Fortaleza na rede urbana brasileira: de cidade à metrópole”. In: COSTA, A. C. L; PEQUENO, R. (eds.). Metrópole: território, coesão social e governança democrática. Fortaleza: Transformações de ordem urbana. Rio de Janeiro, Letra Capital e Observatório das Metrópoles.

DAMIÃO, A. P. (2014). Espaço urbano, produção do espaço e segregação socioespacial: o espaço urbano capitalista e o caso de Marília/SP. Revista do Laboratório de Estudos de Violência da Unesp/Marília. Marília, v. 15, n. 1, pp. 56-70.

DIÓGENES, B. H. N. (2012). Dinâmicas urbanas recentes da área metropolitana de Fortaleza. Tese de doutorado. São Paulo, Universidade de São Paulo.

IBGE (1991). Censo demográfico 1991. Instituto Brasileiro de Geografia e Estatística, IBGE.

(2000). Censo demográfico 2000. Instituto Brasileiro de Geografia e Estatística, IBGE.

(2010). Censo demográfico 2010. Instituto Brasileiro de Geografia e Estatística, IBGE.

(2019). Estimativas da população residente para os municípios e para as unidades da federação brasileiros com data de referência em 1 ํ de julho. IBGE, Diretoria de Pesquisas - DPE, Coordenação de População e Indicadores Sociais - Copis.

IPECE - Instituto de Pesquisa e Estratégia Econômica do Ceará (2018). Mapa das Regionais de Fortaleza. Ipece.

$\mathrm{KOCH}, \mathrm{M}$. R. (2008). Condomínios fechados: as novas configurações do urbano e a dinâmica imobiliária. Indicadores Econômicos FEE. Porto Alegre/RS, pp. 99-116.

LOPES, F. C. R. (2016). A incorporação sob a forma de condomínio horizontal na Região Metropolitana de Fortaleza, Brasil. Mercator. Fortaleza, v. 15, n. 1, pp. 31-41.

MELGAÇO, L. (2012). A cidade de poucos: condomínios fechados e a privatização do espaço público em Campinas. Boletim Campineiro de Geografia. Campinas, v. 2, n. 1, pp. 81-105.

OliVeiRA, Y. M. C. de; MENELEU NETO, J.; OliVEIRA NETO, T. I. de (2018). Paisagem das favelas do bairro Sapiranga/Coité, Fortaleza-CE: vida cotidiana para além da casa. Casa da Geografia. Sobral, v. 20, n. 3, pp. 31-48.

PREFEITURA DE FORTALEZA (2018a). Fortaleza em Mapas. Disponível em: <http://mapas.fortaleza. ce.gov.br/\#/> Acesso em: 18 dez 2018.

(2018b). Plano Plurianual 2018-2021. Disponível em: https://planejamento.fortaleza.ce.gov.br/ images/Planejamento/ParticipacaoSocial/PPA/Regional6/CADERNO-REGIONAL-VI-TERRITORIO31---WEB-PMF.pdf>. Acesso em: 9 maio. 
PREFEITURA DE FORTALEZA. (2020). A Cidade. Disponível em <https://www.fortaleza.ce.gov.br/acidade>. Acesso em: 9 maio.

RAPOSO, R. (2008). Condomínios fechados em Lisboa: paradigma e paisagem. Análise Social. Lisboa, v. 43, n. 1 , pp. $109-131$.

RIBEIRO, D. (2018). Dicio - Dicionário online de português. Disponível em: https://www.dicio.com.br/ segregacao/. Acesso em: 22 dez 2018.

SALVADOR, D. S.; CARLEIAL, A. N. (2010). Leste de Fortaleza: natureza, produção do espaço e o crescimento urbano no bairro Sapiranga/Coité. In: ENCONTRO NACIONAL DOS GEÓGRAFOS, Porto Alegre, v. 1, n. 1, pp. 1-10.

SALVADOR, D. S.; GRANGEIRO; C. M. M. (2014). Urbanização, especulação imobiliária e sistemas ambientais: um estudo sobre o Bairro Sapiranga-Coité em Fortaleza-CE. In: VII CONGRESSO BRASILEIRO DE GEÓGRAFOS. Anais... Vitória.

SANTOS, E. de O. (2013). Segregação ou fragmentação socioespacial? Novos padrões de estruturação das metrópoles latino-americanas. Geotextos. Fortaleza, v. 9, n. 1, pp. 41-70.

SOUZA, M. L. de (2013). Os conceitos fundamentais da pesquisa socioespacial. Rio de Janeiro, Bertrand Brasil.

SPOSITO, M. E. B. (2018). "A produção do espaço urbano: escalas diferenças e desigualdades sociais". In: CARLOS, A. F. A.; SOUZA, M. L. de; SPOSITO, M. E. B. (orgs.). A produção do espaço urbano: agentes, processos, escalas e desafios. São Paulo, Contexto.

TEIXEIRA, A. (2017). Sapiranga é um dos bairros com 'aumento mais expressivo' da violência contra jovens. Globo Ceará. Disponível em: <https://g1.globo.com/ceara/noticia/sapiranga-e-um-dosbairros-com-aumento-mais-expressivo-da-violencia-contra-jovens.ghtml>. Acesso em: $29 \mathrm{dez}$ 2018.

VILLAÇA, F. (2001). Espaço intraurbano no Brasil. São Paulo, Studio Nobel.

Texto recebido em 27/dez/2019

Texto aprovado em 19/abr/2020 
